\title{
Sphingosine-1-Phosphate-Receptor 1 as a Marker for Endothelial Cells in Mouse Xenograft Models of Human Cancer
}

\author{
NADINE LÜDERS and UDO SCHUMACHER \\ Institute of Anatomy and Experimental Morphology, Center for Experimental Medicine, University \\ Cancer Center, University Medical Center Hamburg-Eppendorf, Hamburg, Germany
}

\begin{abstract}
Background/Aim: The sphingosine-1-phosphate $(S 1 P) 1$ receptor $\left(S 1 P_{1} R\right)$ is an important receptor for the modulation of endothelial cell function. We, therefore, wanted to investigate its expression as a blood vessel marker. Materials and Methods: The expression of the SIP receptor $1 \quad\left(S 1 P_{l} R\right)$ in mouse blood vessel endothelium was investigated immunohistochemically in normal blood vessel endothelium and blood vessel endothelium of xenografted human tumors. Results: The $S 1 P_{1}$ receptor was expressed in the endothelium of most mouse organs. Endothelia of the intestinal tract and of adipose tissue showed the strongest immunoreactivity. However, a difference in staining between larger vessels and fenestrated endothelium was observed, whereas fenestrated endothelium expressed a weaker staining. In addition to normal endothelia, most tumor blood vessel endothelia expressed $S 1 P_{1} R$. A particularly strong expression in the endothelium was detected in primary pancreatic and prostate cancer xenografts. In both xenograft tumor entities, no significant difference in staining intensities of the endothelium between arteries, veins and capillaries was observed. Conclusion: As $S 1 P_{1} R$ is expressed in most blood vessel endothelia and in the tumor blood vessel endothelia, it is an ideal blood vessel marker.
\end{abstract}

Generating new capillary blood vessels is a complex process which usually occurs during embryonic development, ovulation, and wound healing. However, this process is also essentially involved in chronic inflammation and tumor growth. While the process of neovascularisation in malignant tissues is partially similar to that in non-malignant tissues, it differs in terms of completion of angiogenesis. While it stops

Correspondence to: Nadine Lüders, University Medical Center Hamburg-Eppendorf, Martinistraße 52, 20246 Hamburg, Germany. Tel: +49 40741053586,Fax: +49 40741055427, e-mail: na.lueders@ gmail.com

Key Words: Endothelium, immunohistochemistry, sphingosine-1phosphate receptor 1 , xenograft cancer models. at the point of completion during physiological processes, angiogenesis in malignant tumors is not self-limited and continues to develop (1). Tumor blood vessels express markers that are normally not present in resting blood vessels but are expressed under the conditions mentioned above (2). Hence, it is not astonishing that the expression of different markers for endothelial cells, used to determine the microvessel density in human tumors, gave different results concerning the prognostic value of microvessel density depending on the marker (3).

In order to precisely detect endothelial cells of tumor blood vessels a common marker or a panel of markers ideally labelling all endothelial cells of the tumor vasculature is desirable. To identify a protein with such potential, we searched for a marker physiologically expressed during blood vessel formation. One of the earliest events in forming new blood vessels in normal vasculogenesis is mediated by the sphingosine-1-phosphate (S1P) signaling pathway (4). The lysophospholipid sphingosine-1-phosphate is a potent lipid mediator of extracellular signaling pathways and exerts its effect by transduction into intracellular signals for various guanine nucleotide binding proteins (G-protein)-coupled receptors: the S1P receptors (S1PR) (5). The first receptor in the aforementioned family is $\mathrm{S}_{1} \mathrm{P}_{1} \mathrm{R}$, previously known as endothelial differentiation gene $1(E d g-1)$, since it was first identified as a gene that up-regulated its expression after endothelial cells formed tubular structures in vitro (6). S1P signaling plays an important role in vasculogenesis as well as in angiogenesis. Investigations provided evidence that the signaling promotes endothelial cell invasion, lumen formation, and branching morphogenesis into 3D collagen and fibrin matrices (7). Furthermore S1P signaling plays a critical role in acute vascular inflammation $(8,9)$. The balance in the expression and activation of $\mathrm{S}_{1} \mathrm{P}_{1} \mathrm{R}, \mathrm{S}_{1} \mathrm{P}_{2} \mathrm{R}$ and $\mathrm{S} 1 \mathrm{P}_{3} \mathrm{R}$ is here very important as extracellular mediators can up- or downregulate the expression of the specific receptor (10).

$\mathrm{We}$, therefore, investigated the expression of $\mathrm{S}_{1} \mathrm{P}_{1} \mathrm{Rs}$ in the endothelium of scid mouse organs and of tumor blood vessels of subcutaneously xenografted human primary tumors derived from human cancer cell lines. 


\section{Materials and Methods}

Histology and immunohistochemistry. For the investigation of the normal blood vessel endothelium, seven months old scid mice were sacrificed after Ketamin/Rompun anaesthesia by cervical dislocation. Heart, lung, intestinal tract, pancreas, liver, spleen, kidney, adrenal gland, muscle, adipose tissue, brain, and spinal cord were removed and fixed in $4 \%$ neutral buffered formalin and processed to paraffin wax.

Paraffin wax blocks of the primary xenografted tumors were drafted from the files of the Department of Anatomy and Experimental Morphology. The previous experiments from which the wax blocks were derived were performed according to the United Kingdom Co-ordinating Committee on Cancer Research (UKCCR) guidelines for the welfare of animals (11). The experiments were supervised by the animal welfare officer and the experiments were approved by the local licensing authority (Behörde für Soziales, Familie, Gesundheit, Verbraucherschutz, Amt für Gesundheit und Verbraucherschutz, Billstraße 80, D-20539 Hamburg) under the numbers $09 / 88 ; 67 / 07 ; 58 / 08$. The following primary xenografted tumors were investigated: breast cancer (T47D, MCF7, DU4475), neuroblastoma (SKNSH, LAN1, LAN5, Kelly, IMR32, LS), lung cancer (H69, H82, OH1), prostate cancer (LNCAP, Lucap, PC3, Du145), melanoma (Femx1, Mewo, Lox, MV3, MDAMB435), pancreatic cancer (PaCa 5072, PaCa 5061), colon cancer (HT29, $\mathrm{CaCo} 2, \mathrm{SW} 480$ ), and ovarian cancer (SKOV3, OC2, OVCAR) cell lines. For further information concerning the origin of the cell lines and the experiments from which they were derived see $(12,13,14$, $15,16,17)$. The cell lines SKOV3 and OVCAR3 were purchased from the American Type Culture Collection (ATCC, Manassas, VA, USA; No. HTB-77 and HTB-161), OC2 was kindly provided by Dr. Georg Brunner, Fachklinik Hornheide.

Four $\mu \mathrm{m}$ thick sections were deplastinated by xylene and rehydrated by a series of graded ethanol to water and then incubated in a hot water bath $\left(85^{\circ} \mathrm{C}\right)$ for $16 \mathrm{~h}$ in Target Retrieval Solution (S1699; Dako, Glostrup, Denmark). After antigen retrieval, sections were placed into distilled water. For ten min non-specific biotin binding sites were blocked by the Biotin Blocking System (X0590; Dako, Glostrup, Denmark) at room temperature. Afterwards, the sections were incubated in protein block (serum-free protein in PBS with $0.015 \mathrm{~mol} / \mathrm{L}$ sodium azide) for $20 \mathrm{~min}$ at room temperature. This was followed by incubation with the rabbit polyclonal primary antibody against amino acids 322-381 of $\mathrm{S}_{1} \mathrm{P}_{1} \mathrm{R}$ (Edg-1, H60; Santa Cruz, CA; sc-25489) at $4^{\circ} \mathrm{C}$ overnight, diluted 1:8,000 with Antibody Diluent (S2022; Dako, Glostrup, Denmark). The rabbit isotype IgG (X0903; Dako, Glostrup, Denmark) diluted to the same concentration of the IgG as the primary antibody $(1: 800,000)$ was used as a negative control. Both anti-S1 $\mathrm{P}_{1} \mathrm{R}$ and control antibody were incubated with biotinylated swine anti-rabbit polyclonal secondary antibody (E0353; Dako, Glostrup, Denmark), diluted 1:200 for $20 \mathrm{~min}$ at room temperature. All ingredients were part of the Catalyzed Signal Amplification (CSA) System (K1500; Dako, Glostrup, Denmark). The sections were first incubated in streptavidin-biotin complex for $15 \mathrm{~min}$ at room temperature and then in Biotinyl tyramide Amplification Reagent for $15 \mathrm{~min}$. For detection a Streptavidin Alkaline Phosphatase (K5005; Dako, Glostrup, Denmark) was used for $15 \mathrm{~min}$ at room temperature and Liquid Permanent Red Chromogen (K0640; Dako, Glostrup, Denmark) was finally added for ten min at room temperature. The sections were then washed in tap water for five min, counterstained with Mayer's Hämalaun 1:1 for four seconds, blued in tap water, and then mounted with Aquatex (1.08562.0050; Merck, Darmstadt, Germany). Except for the protein block and the primary antibody incubation step, respectively, the sections were washed once with TBS, afterwards three times with TBST and finally once with TBS between each incubation step.

Staining evaluation and statistical analysis. The staining intensity was categorized into an ordinal scale: very weak or no $(\bigcirc)$ staining, weak $(+)$, intense $(++)$ and very intense $(+++)$ staining. The sections were examined under a Zeiss Axioplan photomicroscope and documented using a Zeiss MRc5 digital camera. To ensure an objective assessment of the slides, they were blinded throughout their evaluation.

\section{Results}

$S 1 P_{1} R$ expression in normal blood vessel endothelium of several organs. For the expression of $\mathrm{S}_{1} \mathrm{P}_{1} \mathrm{Rs}$ in the endothelium of normal blood vessels see Table I.

Heart and large blood vessels. Endothelium of large arteries, such as the aorta and truncus pulmonalis, demonstrated a medium expression (++) of $\mathrm{S}_{1} \mathrm{P}_{1} \mathrm{Rs}$ immunoreactivity. Endothelium of coronary arteries had a medium staining $(++)$, whereas cardiac veins showed a less intensive $(+)$ staining. Within the whole myocardium medium staining $(++)$ of the endothelium of the capillaries was found (Figure 1a). A medium (++) expression was also noted on the endocardium of the heart valves.

Lung. The larger and mid-sized vessels that permeate throughout the lung had a medium expression (++) of the receptor (Figure 1b). Larger veins, compared to larger arteries, had a weaker staining (+), small vessels and capillaries showed a medium staining $(++)$.

Vessels (arteries and veins) that are located next to the ramifications of the bronchial tree, belonging to the vasa publica, showed a stronger staining $(+++/++)$ compared to the smaller vessels of the vasa privata. Capillaries showed a medium staining $(++)$. Only occasionally, even the covering type-I epithelium of the alveolar septum was stained weakly (+).

Intestinal tract. A strong intensity of immunoreactivity (+++) of the blood vessel endothelium was found within most areas of the intestinal tract. In general, no differences between arteries and veins were observed. The staining of capillary endothelium was always a little weaker $(+/++)$ compared to larger vessels.

Starting with the esophagus, a strong staining (+++) of the endothelium of arteries, veins and capillaries was observed within the tunica serosa, as well as occasionally a weak staining of vessels (+) within the tela submucosa. In some regions larger veins showed a weaker staining compared to the rest of the stained vessels. 
Table I. Comparative analysis of sphingosine-1-phosphate receptor 1 expression within normal blood vessel endothelium of several organs.

\begin{tabular}{lcc}
\hline & Tissue or organ & ${\mathrm{S} 1 \mathrm{P}_{1} \mathrm{R} \text { expression }}$ \\
\hline Heart & Endocardium & ++ \\
& Cardiac valve & ++ \\
& Coronaries & +++ \\
Great vessels & ++ \\
Lung & & ++ \\
Intestinal tract & Esophagus & ++ \\
& Stomach & +++ \\
Pancreas & Intestine & +++ \\
Liver & & +++ \\
Spleen & & + \\
Kidney & & ++ \\
Adrenal & & ++ \\
Voluntary muscle & & + \\
Fat & & ++ \\
Brain & & +++++ \\
Spinal cord & & ++ \\
\hline
\end{tabular}

The staining intensity of the receptor was recorded as negative $(\bigcirc)$; weak $(+)$; intense $(++)$; very intense $(+++)$. Number of sections evaluated in total: 14 .

The expression of $\mathrm{S}_{1} \mathrm{P}_{1} \mathrm{R}$ in endothelial cells in the stomach was very strong (+++) and most of the vessels were found in the tunica serosa. As observed in the tunica serosa and tela submucosa the stained vessels within the rest of the intestinal tract were very frequently intensivels stained $(+++)$. In each cross-section of the villi at least one stained vessel with a high intensity (+++) was found (Figure 1c).

In addition to the stained endothelium in the esophagus, a medium staining (++) was also detected at the surface of the esophageal basal cells.

Pancreas. The expression of the $\mathrm{S}_{1} \mathrm{P}_{1} \mathrm{Rs}$ within the pancreas varied. A medium intensity of staining $(++)$ of endothelium of the arteries and veins was observed in the vessels surrounding the islets of Langerhans. Stained capillaries were not detected within the islets. The staining of the capillary endothelium was medium $(++)$ within the exocrine pancreas (Figure 1d).

Liver. In the liver, the expression of the $\mathrm{S}_{1} \mathrm{P}_{1} \mathrm{R}$ was weak in the endothelium of the sinusoids $(+)$. No stained central vein could be found $(\bigcirc)$. Within the portal triad a weak staining $(+)$ of the endothelium of the portal veins and hepatic arteries was detected.

Spleen. The central arteries within the trabeculae had a medium expression of the receptor $(++)$, as well as central arteries within the white pulp (Figure 1e). No stained sinus or pulp veins were detected. Nevertheless, no staining of the endothelium within the red pulp (splenic sinus) could be detected.

Kidney. The endothelium of the greater vessels in the cortex of the kidney (Aa. and Vv. interlobulares) had a medium staining (++), as well as the arteriola afferens and efferens next to the glomeruli (Figure 1f). The fenestrated endothelium of the capillaries in the glomeruli and the capillaries in the renal medulla demonstrated no staining (O). Vessels on the margins of the pyramis renalis (Aa. and Vv. interlobares) had a medium staining (++).

Adrenal gland. Inside the adrenals, a varied expression of S1 $\mathrm{P}_{1} \mathrm{R}$ was observed. The staining of the endothelium of larger vessels (arteries and veins) within the capsule and the septa was much more intense $(++)$ compared to the staining within the medulla of the adrenal glands. Here the expression of the endothelium of the vessels with $\mathrm{S}_{\mathrm{P}} \mathrm{P}_{1} \mathrm{Rs}$ was weak (+) and no immunoreactivity within the sinusoid endothelium was observed $(\bigcirc)$.

Muscle and adipose tissue. The muscle and adipose tissue generally showed medium staining of endothelium (++) but differed depending on the origin tissue. The muscle tissue that has been used in this study was heart muscle and voluntary muscle (especially the tongue).Vessels in both tissues showed a medium expression (++) of the receptor at the endothelium. A difference of the intensity of staining in arteries, veins and capillaries could not be made.

In general the staining of endothelium within the septa of adipose tissue was medium intense $(++)$. Differences between localizations were visible, whereas vessels in the visceral fat of abdominal organs always had a strong staining $(+++$, see Figure 1g), compared to vessels in other adipose tissue (++). No difference of intensity of staining was detected between arteries or capillaries, whereas larger veins showed a weaker staining (+/++).

Brain and spinal cord. No endothelial staining of blood vessels within the brain at any region, neither gray nor white matter, could be identified. Endothelium of vessels surrounding the brain, in the subarachnoid space, had a medium staining (++). In some regions of the choroid plexus a weak staining of the fenestrated endothelium was present $(+)$. At the surface of the brain, a medium staining (++) of the membrane glia limitans superficialis (astrozytes) existed. Stained vessels within the spinal cord could not be detected. The endothelium of larger vessels (Aa. spinales and Vv. spinales) that grow alongside the spinal cord was strongly stained $(+++)$.

A reticular network of fibers of the white matter was detected in the spinal cord. The entire grey matter of the spinal 
cord was labeled by $\mathrm{S}_{1} \mathrm{P}_{1} \mathrm{R}$. The posterior aspect of the dorsal horn is particularly well labeled (see Figure $1 \mathrm{~h}$ ). No staining of cells of white matter in the brain was detected.

$S 1 P_{1} R$ expression in tumor blood vessels. For the staining of $\mathrm{S}_{1} \mathrm{P}_{1} \mathrm{R}$ in endothelium of tumor blood vessels within eight different xenografted tumor entities see Table II.

Breast cancer. For the analysis four different breast cell lines (T47D, MCF7, DU4475) were used. The expression of the $\mathrm{S}_{1} \mathrm{P}_{1} \mathrm{R}$ was medium (++) within the endothelium of most primary xenograft tumors (see Figure 2a for DU4475), with the exception of MCF7, where no staining of endothelium within MCF7 primary tumor was detected $(\bigcirc)$. When present, no differences in the staining intensities of the endothelium between arteries and veins were observed $(+++)$; the capillaries were less intensively stained $(+)$.

Neuroblastoma. Six different neuroblastoma lines (SKNSH, LAN1, LAN5, Kelly, IMR32, LS) were used to identify the expression of $\mathrm{S}_{1} \mathrm{P}_{1} \mathrm{Rs}$ in the tumor blood vessels. In general, endothelium of all neuroblastoma xenografts showed medium staining $(++)$ : The strongest staining was detected in endothelium of the arteries $(+++/++)$, veins showed a medium staining intensity $(++)$, whereas capillaries were less intensively stained (+).

Lung cancer. The expression of $\mathrm{S}_{1} \mathrm{P}_{1} \mathrm{Rs}$ in vessels of the tumor capsules was always very strong $(+++)$ in all three cell lines (H69, H83, OH1). Within two tumor lines (H69 and H83) a large central necrosis was observed and the $S 1 P_{1} R$ expression in the intact capillaries near the necrotic center was weak or even absent $(\bigcirc)$. The staining of the endothelium of the vessels at the rim of H69 and H83 tumors was strong or medium $(+++/++)$. Compared to other vessels, the capillaries within the tumor had weaker staining $(+)$. The vessels within $\mathrm{OH} 1$ tumors were sufficiently stained in all parts (++) and no differences between the staining of arteries and capillaries could be recognized.

Prostate cancer. Xenograft tumors from LNCAP, Lucap, PC3 cells showed a strong expression (+++) of $\mathrm{S}_{1} \mathrm{P}_{1} \mathrm{Rs}$ in the endothelium of blood vessels with no differences between arteries, veins and capillaries (see Figure $2 b$ for LNCAP). Compared to other tumors, a medium staining (++) was observed explicitly in sections of Du145.

Melanoma. Most of the four melanoma cell line (Femx1, Mewo, Lox, MV3, MDAMB435) xenograft tumors had medium (++) or strong (+++) expression of $\mathrm{S}_{1} \mathrm{P}_{1} \mathrm{Rs}$ within the endothelium of blood vessels, while the labeling of Femx1 was weak (+). Lox and MV3 (Figure 2c) xenografts showed a strong staining $(+++)$ throughout vessels in the entire tumor, whereas
Table II. Comparative analysis of sphingosine-1-phosphate receptor 1 expression within tumor blood vessels of human tumor cell lines.

\begin{tabular}{|c|c|c|}
\hline Cancer entity & $\begin{array}{l}\text { Total number of } \\
\text { sections (n) }\end{array}$ & $\begin{array}{c}\mathrm{S}_{1} \mathrm{P}_{1} \mathrm{R} \\
\text { expression }\end{array}$ \\
\hline Breast cancer & 10 & ++ \\
\hline T47D & 5 & $+/++$ \\
\hline MCF7 & 2 & 0 \\
\hline DU4475 & 3 & ++ \\
\hline Neuroblastoma & 29 & ++ \\
\hline SKNSH & 5 & ++ \\
\hline LAN1 & 5 & ++ \\
\hline LAN5 & 5 & ++ \\
\hline Kelly & 4 & $++/+++$ \\
\hline IMR32 & 5 & + \\
\hline LS & 5 & ++ \\
\hline Lung cancer & 11 & ++ \\
\hline H69 & 4 & $++/+++$ \\
\hline H82 & 3 & $++/+++$ \\
\hline $\mathrm{OH} 1$ & 4 & ++ \\
\hline Prostate cancer & 15 & +++ \\
\hline LNCAP & 4 & +++ \\
\hline Lucap & 3 & +++ \\
\hline $\mathrm{PC} 3$ & 4 & +++ \\
\hline Du145 & 4 & $++/+++$ \\
\hline Melanoma & 21 & ++ \\
\hline Femx 1 & 4 & + \\
\hline Mewo & 4 & ++ \\
\hline Lox & 4 & +++ \\
\hline MV3 & 4 & +++ \\
\hline MDAMB435 & 5 & ++ \\
\hline Pancreas cancer & 7 & ++ \\
\hline $\mathrm{PaCa} 5072$ & 3 & ++ \\
\hline $\mathrm{PaCa} 5061$ & 4 & +++ \\
\hline Colon cancer & 11 & ++ \\
\hline HT29 & 4 & ++ \\
\hline $\mathrm{CaCo} 2$ & 4 & +++ \\
\hline SW480 & 3 & ++ \\
\hline Ovarian cancer & 12 & +++ \\
\hline SKOV3 & 4 & +++ \\
\hline $\mathrm{OC} 2$ & 4 & +++ \\
\hline OVCAR & 4 & 0 \\
\hline
\end{tabular}

The staining intensity of the receptor was recorded as negative $(\bigcirc)$; weak $(+)$; intense $(++)$; very intense $(+++)$. Number of sections evaluated in total: 116 .

Mewo showed medium staining (++) only near the edge of the tumor due to a large central necrosis. No differences between arteries, veins and capillaries were observed.

Pancreatic cancer. The expression of the $\mathrm{S}_{1} \mathrm{P}_{1} \mathrm{Rs}$ in vessels in pancreatic tumors differed. In $\mathrm{PaCa} 5072$ xenografts the staining of the endothelium was medium (++) and very strong (+++) in $\mathrm{PaCa} 5061$ xenografts (Figure 2d). In sections of $\mathrm{PaCa} 5072$ xenografts, most vessels were found within the stroma of the tumor and its capsule. Capillaries had a stronger staining intensity (++) compared to the larger 
vessels (+). In sections of $\mathrm{PaCa} 5061$ xenografts, within the entire tumor, a very strong staining $(+++)$ of all endothelial cells of all vessel types was recorded. Most blood vessels were surrounded by a well developed tumor stroma.

Colon cancer. Staining within the three colon cancer xenografts (HT29, CaCo2, SW480) differed between medium (++) in HT29 and SW480, and strong (+++) in CaCo2. HT29 and SW480 showed a consistent staining of endothelial cell of all vessel types in all areas of the tumor, including capsule, stroma and central areas. Vessels in the tumor capsule demonstrated a strong staining (+++) in HT29 and SW480 xenografts.

Ovarian cancer. All types of blood vessel endothelium in SKOV3 ovarian cancer xenografts showed a medium

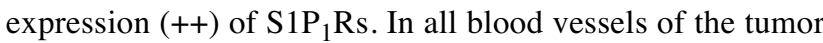
line OC2 a strong expression (+++) of $\mathrm{S}_{1} \mathrm{P}_{1} \mathrm{Rs}$ (arteries, veins and capillaries) was observed. In contrast, blood vessels in OVCAR cell xenografts did not show any expression of $\mathrm{S}_{1} \mathrm{P}_{1} \mathrm{Rs}$ within blood vessels $(\bigcirc)$.

\section{Discussion}

This study describes the expression of the $\mathrm{S}_{1} \mathrm{P}_{1} \mathrm{R}$ within the endothelium of blood vessels in normal organs and in primary tumor xenografts in scid mice. The $\mathrm{S}_{1} \mathrm{P}_{1} \mathrm{R}$ is one of the important mediators for vascular maturation $(18,19)$. Therefore, it may be essential to explore its prevalence not only within the endothelium of vessels in normal organs, but also within the endothelium of tumor blood vessels, where angiogenesis is an important mechanism to sustain continued tumor growth.

In previous studies it has been discussed that the sphingosine-1-phosphate receptor 1 is an essential factor for the growth of new blood vessels (18) and therefore may be essential for tumor growth. Krump-Kovalinkova et al. concluded that knockout mice die in utero and therefore $\mathrm{S}_{1} \mathrm{P}_{1} \mathrm{R}$ must be essential for living, survival and migration, and showed that $\mathrm{S}_{1} \mathrm{P}_{1} \mathrm{R}-\mathrm{RNA}$ is expressed in human endothelial cells (HUVEC) (20); Chae et al. concluded that intra-tumoral vessels of specific lung carcinoma cells express the $S 1 P_{1} R$ (19). This study expanded the search for more carcinoma types and investigated the occurrence of the receptor within various tumor blood vessels and blood vessels of normal mouse tissues.

Describing the expression of $\mathrm{S}_{1} \mathrm{P}_{1} \mathrm{Rs}$ within the endothelium of normal organs, it has been shown that most organs express at least a medium intensity $\mathrm{S}_{1} \mathrm{P}_{1} \mathrm{R}$ immunoreactivity in the endothelium of their blood vessels. In addition to endothelial cells, not many cell types (type I epithelium of the alveolar septum, esophageal basal cells, glia limitans, cells of the gray matter of the spinal cord) were stained, especially no tumor cells. Hence, this staining is a relatively endothelial cellspecific. For endothelial cells, this cell type specificity is more beneficial compared to CD34 staining, as CD34 is also expressed in haematopoietic stem cells.

We could not identify a staining in lymphatic vessels, but Yoon et al. showed that lymphangiogenesis is stimulated by S1P1-signaling pathways (21). We focused our search into blood vessels, but an expansion and a comparison between lymphatic and blood vessels could be subject of further investigation, especially since inverstigations showed a role of the S1P3R in lymphangiogenesis (22).

Even though some tissues, such as intestinal tract and adipose tissue, strongly express the receptors in the endothelial cells, other organs do not show an intensive staining, such as the liver (only a weak staining of vessels in the portal triad) and adrenals (strongest staining of vessels in the capsule and no immunoreactivity within the sinusoid endothelium). In general, a strong staining in larger vessels and vessels of organ and tumor capsules was present.

Further assessments concerning adequate staining in greater vessels (e.g., aorta and truncus pulmonalis) compared to microvessels (e.g., in heart, in intestine, and fenestrated endothelium) can be carried out. However, only a weak or even no staining in areas of fenestrated endothelium (such as the sinusoides of the liver and the spleen, in the glomeruli of the kidney or the plexus choroideus) was detected. In general, fenestrated endothelia do not express the receptor well; however, endothelium of the gastrointestinal tract, which is also fenestrated, shows a very strong staining of the receptor and is thus an exception to this observation. A reason for this could be the extremely high proliferation rate in the intestinal tract, but this is a topic to be further investigated in other studies.

In general, afferent and efferent vessels surrounding the organs and passing through connective tissue or the capsule had a stronger staining compared to the staining of smaller vessels or capillaries permeating the organs. Microvessels show a weaker expression of the $\mathrm{S}_{1} \mathrm{P}_{1} \mathrm{R}$ and it can be discussed if the regulation mediated by S1P1 in these vessels is lesser important.

In addition, a strong staining of endothelium in the visceral white adipose tissue was observed. As visceral fat is well vascularized, $\mathrm{S}_{1} \mathrm{P}_{1} \mathrm{R}$ expression in the endothelium is a reflection of the strong cooperation between fat cells and endothelium as in many other endothelia the $S 1 P_{1} R$ expression is less pronounced.

In the central nervous system $\mathrm{S}_{1} \mathrm{P}_{1} \mathrm{R}$ immunoreactivity was detected in vessels located in the subarachnoid space and in some regions of the choroid plexus. No staining was detected in vessels within the brain while other cells in the brain express $\mathrm{S}_{1} \mathrm{P}_{1} \mathrm{R}, e . g$. astrocytes and especially those that constitute the glia limitans. Similar results were published by Nishimura et al. who explored the expression of the $\mathrm{S}_{1} \mathrm{P}_{1} \mathrm{R}$ within the human central nervous system. They discovered that the glia limitans and the luminal surface of the endothelial cells were also stained (23). Recently it could also be shown that the $\mathrm{S}_{1} \mathrm{P}_{1} \mathrm{R}$ plays a role in the blood-brain barrier (24). 

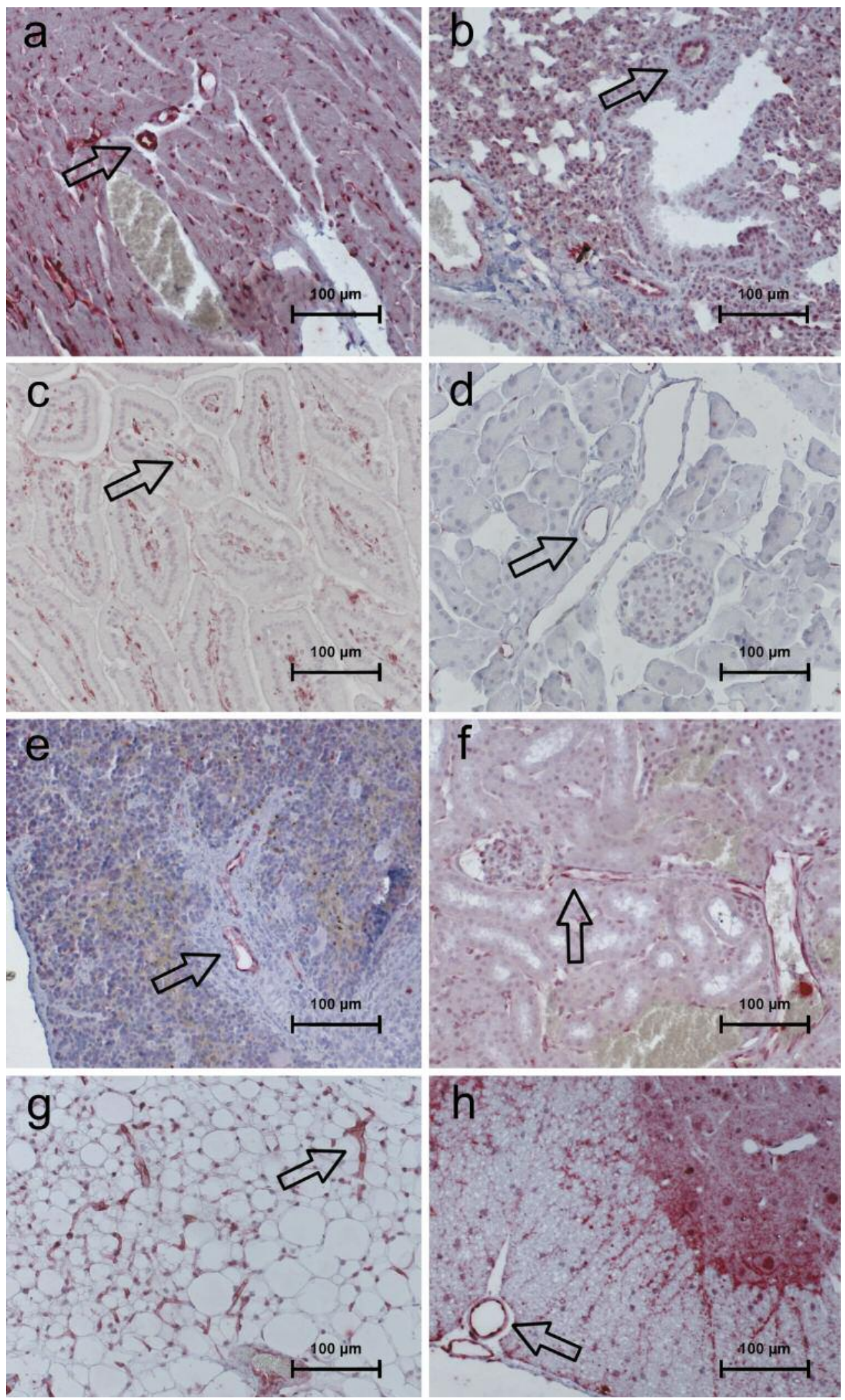

Figure 1. Expression of S1P1R within normal blood vessel endothelium of several organs. Expression of the receptor on the endothelium of vessels in: a) the heart tissue, $b$ ) the lung, c) the intestine tract, d) the pancreas, e) the spleen, $f$ ) the kidney, g) visceral fat tissue, $h$ ) the spinal cord. 

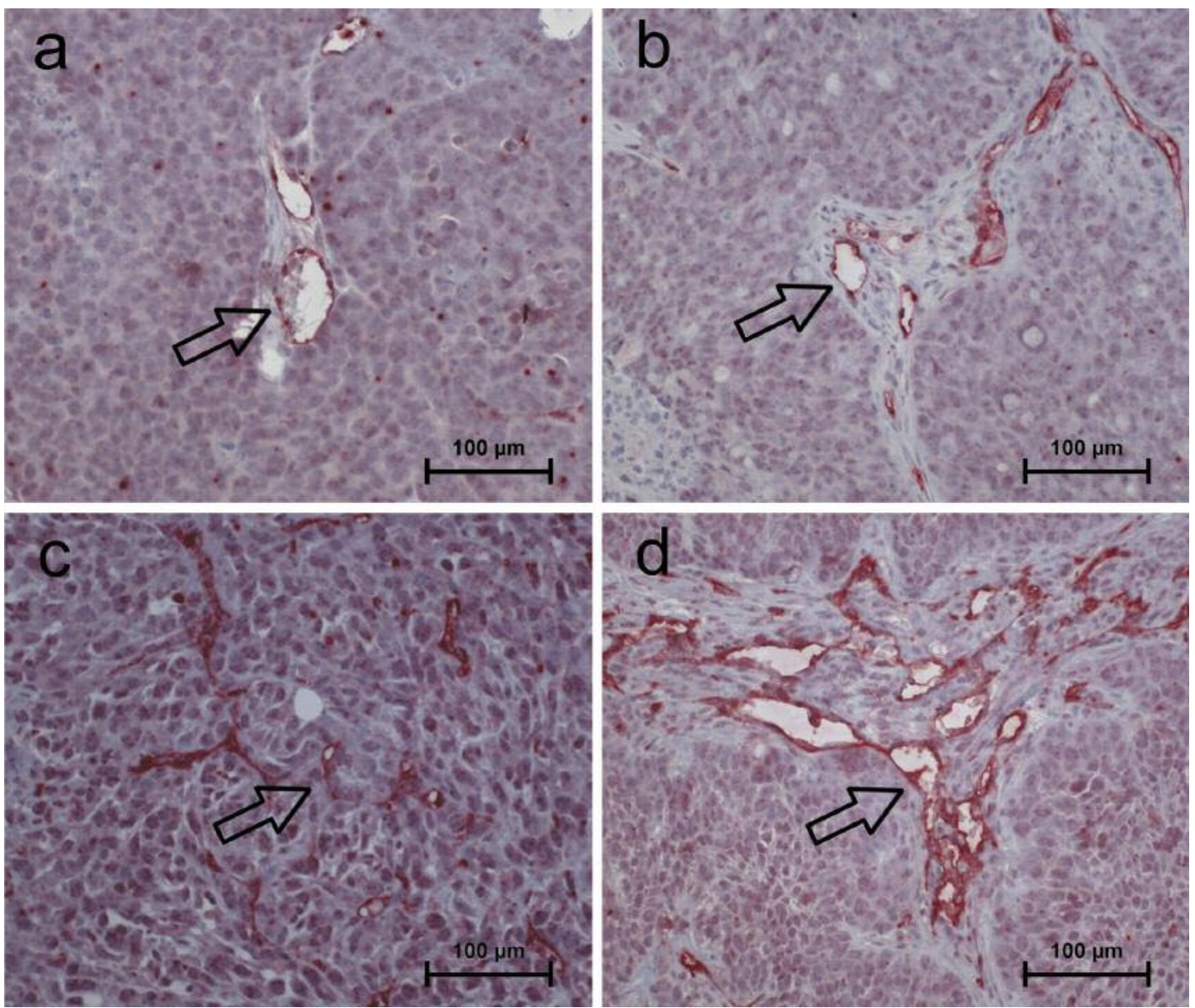

Figure 2. Expression of the S1P1R within blood vessels of xenografted tumors. Expression of the receptor on the endothelium of vessels in: a) breast cancer (DU4475), b) prostate cancer (LNCAP), c) melanoma (MV3), d) pancreas cancer (PaCa 5061).

In this study we have shown that the $\mathrm{S}_{1} \mathrm{P}_{1} \mathrm{R}$ is largely expressed within the endothelium of mouse blood vessels. The receptor also occurs in most of the blood vessels' endothelium within tumors, so that is well suited to identify capillaries as well. Some examples of particularly strong immunoreactivity are blood vessel endothelia of primary prostate and pancreatic cancer xenografts. In these examples a very high intensity of staining in vessels within the entire tumor can be observed.

Most tumor blood vessel endothelia show a similar $\mathrm{S}_{1} \mathrm{P}_{1} \mathrm{R}$ expression pattern. Whereas vessels near the tumor margins demonstrate stronger staining, the staining of vessels get paler the closer they are located to the tumor's center. In several tumors' centers (neuroblastoma, lung cancer, prostate cancer, melanoma, pancreatic cancer and colon cancer), areas of central necrosis were found. However, since central necrosis is a common feature often caused by chronic ischemia this feature may be the reason of insufficient nourishment or rapid tumor growth (25) and lead to a loss of vital tumor and blood vessel endothelia. Based on the discussion above, it can be postulated that a correlation between the central necrosis and the lesser expression of vessels and $\mathrm{S}_{1} \mathrm{P}_{1} \mathrm{R}$ expression exists. Furthermore, vessels within the capsule of the tumor always reveal a very strong staining. This expression phenotype was found within all tumor types that have been part of the investigation described above (especially breast cancer, neuroblastoma, and lung cancer).

Finally, the experiments show that all investigated tumor lines express the receptor well on endothelial cells. Overall, all tumor lines have at least a weak staining, with the exception of the ovarian cancer cell line OVCAR and the breast cancer cell line MCF7, which express no staining of the receptor in their blood vessels. The reasons for this absence of immunoreactivity are unclear so far.

\section{Conflicts of Interest}

The Authors declare that no competing interests exist. 


\section{Acknowledgements}

The Authors would like to thank Dorothee Köhler for the experienced help she provided at the beginning of this project.

\section{References}

1 Folkman J: Tumor Angiogenesis. Adv Cancer Res 43: 175-203, 1985.

2 Ruoslahti E: Specialization of tumor vasculature. Nat Rev Cancer 2: 83-90, 2002.

3 Giatromanolaki A, Koukourakis MhI, Theodossiou D, Barbatis $\mathrm{K}$, O'Byrne $\mathrm{K}$, Harris $\mathrm{AL}$ and Gatter $\mathrm{KC}$ : Comparative evaluation of angiogenesis assessment with anti-factor-VIII and anti-CD31 immunostaining in non-small cell lung cancer. Clin Cancer Res 3: 2485-2492, 1997.

4 Argraves KM, Wilkerson BA, Argraves WS, Fleming PA, Obeid LM and Drake CJ: Sphingosine-1-phosphate signaling promotes critical migratory events in vasculogenesis. J Biol Chem 279: 50580-50590, 2004.

5 Meyer zu Heringdorf D and Jakobs KH: Lysophospholipid receptors: signaling, pharmacology and regulation by lysophospholipid metabolism. Biochim Biophys Acta 17668: 923-940, 2007.

6 Hla $\mathrm{T}$ and Maciag T: An abundant transcript induced in differentiating human endothelial cells encodes a polypeptide with structural similarities to G-protein-coupled receptors. J Biol Chem 265: 9308-9313, 1990.

7 Bayless KJ and Davis GE: Sphingosine-1-phosphate markedly induces matrix metalloproteinase and integrin-dependent human endothelial cell invasion and lumen formation in threedimensional collagen and fibrin matrices. Biochem Biophys Res Commun 312: 903-913, 2008.

8 Zhang W, An J, Jawadi H, Siow DL, Lee JF, Zhao J, Gartung A, Maddipati KR, Honn KV, Wattenberg BW and Lee, MJ: Sphingosine-1-phosphate receptor-2 mediated NFKB activation contributes to tumor necrosis factor- $\alpha$ induced VCAM- 1 and ICAM-1 expression in endothelial cells. Prostag Oth Lipid M 106: 62-71, 2013.

9 Du Y, Zeng C, Li Q, Chen B, Liu H, Huang X and Huang Q: LPS and TNF- $\alpha$ induce expression of sphingosine-1-phosphate receptor-2 in human microvascular endothelial cells. Pathol Res Pract 208: 82-8, 2012.

10 Zhang G, Yang L, Kim GS, Ryan K, Lu S, O’Donnell RK, Spokes K, Shapiro N, Aird WC, Kluk MJ, Yano K and Sanchez T: Critical role of sphingosine-1-phosphate receptor 2 (S1PR2) in acute vascular inflammation. Blood 122: 443-55, 2013.

11 Workman P, Aboagye E O, Balkwill F, Balmain A, Bruder G, Chaplin DJ, Double JA, Everitt J, Farningham DA, Glennie MJ, Kelland LR, Robinson V, Stratford IJ, Tozer GM, Watson S, Wedge SR and Eccles SA: Committee of the National Cancer Research Institute. Guidelines for the welfare and use of animals in cancer research. BrJ Cancer 102: 1555-1577, 2010.

12 Müller R, Berliner C, Leptin J, Pörtner D, Bialecki W, Kleuser $B$, Schumacher $U$ and Milicevic NM: Expression of sphingosine-1-phosphate receptors and lysophosphatidic acid receptors on cultured and xenografted human colon, breast, melanoma, and lung tumor cells. Tumor Biol 31: 341-349, 2010.

13 Thies A, Mauer S, Fodstad O and Schumacher U: Clinically proven markers of metastasis predict metastatic spread of human melanoma cells engrafted in scid mice. Br J Cancer 96: 609-616, 2007.
14 Valentiner U, Hall D, Brooks S A and Schumacher U: HPA binding and metastasis formation of human breast cancer cell lines transplanted into severe combined immunodeficient (scid) mice. Cancer Letters 219: 233-242, 2004.

15 Heine M, Freund B, Nielsen P, Jung C, Reimer R, Hohenberg H, Zangenmeister-Wittke U, Wester HJ, Lüers GH and Schumacher U: High Interstitial Fluid Pressure Is Associated with Low Tumor Penetration of Diagnostic Monoclonal Antibodies Applied for Molecular Imaging Purposes. PLoS ONE 7: e36258, 2012.

16 Valentiner U, Haane C, Nehmann N and Schumacher U: Effects of bortezomib in human neuroblastoma cells in vitro and in a metastatic xenograft model. Anticancer Res 29: 1219-25, 2009.

17 Lange T, Ullrich S, Müller I, Nentwich MF, Stübke K, Feldhaus S, Knies C, Hellwinkel OJ, Vessella RL, Abramjuk C, Anders M, Schröder-Schwarz J, Schlomm T, Huland H, Sauter G and Schumacher U: Human prostate cancer in a clinically relevant xenograft mouse model: identification of $\beta(1,6)$-branched oligosaccharides as a marker of tumor progression. Clin Cancer Res 18: 1364-73, 2012.

18 Liu Y, Wada R, Yamashita T, Mi Y, Deng CX, Hobson JP, Rosenfeldt HM, Nava VE, Chae SS, Lee MJ, Liu CH, Hla T, Spiegel S and Proia RL: Edg-1, the G protein-coupled receptor for sphingosine-1-phosphate, is essential for vascular maturation. J. Clin Invest 106: 951-961, 2000.

19 Chae SS, Paik JH, Furneaux H and Hla T: Requirement for sphingosine 1-phosphate receptor-1 in tumor angiogenesis demonstrated by in vivo RNA interference. The J Clin Invest 114: 1082-1089, 2004.

20 Krump-Kanvalinkova V, Yasuda S, Rubic T, Makarova N, Mages J, Erl W, Vosseler C, Kirkpatrick CJ, Tigyi G and Siess W: Stable Knock-Down of the Sphingosine 1-Phosphate Receptor S1P1 Influences Multiple Functions of Human Endothelial Cells. Arterioscler Thromb Vasc Biol 25: 546-52, 2004.

21 Yoon CM, Hong BS, Moon HG, Lim S, Suh PG, Kim YK, Chae $\mathrm{CB}$ and Gho YS: Sphingosine-1-phosphate promotes lymphangiogenesis by stimulating $\mathrm{S} 1 \mathrm{P} 1 / \mathrm{Gi} / \mathrm{PLC} / \mathrm{Ca}^{2+}$ signaling pathways. Blood 112: 1129-38, 2008.

22 Yu M, Zhang H, Liu Y, He Y, Yang C, Du Y, Wu M, Zhang G and Gao F: The cooperative role of S1P3 with LYVE-1 in LMW-HA-induced lymphangiogenesis. Exp Cell Res 336: 1507, 2015.

23 Hirotake N, Akiyama T, Irei I, Hamazaki S and Sadahira Y: Cellular Localization of Sphingosine-1-phosphate Receptor 1 Expression in the Human Central Nervous System. J Histochem Cytochem 58: 847-856, 2010.

24 Yanagida K, Liu CH, Faraco G, Galvani S, Smith HK, Burg N, Anrather J, Sanchez T, Iadecola C and Hla T: Size-selective opening of the blood-rain barrier by targeting endothelial sphingosine 1-phosphate receptor 1. Proc Natl Acad Sci USA 114: 4531-4536, 2017.

25 Leek RD, Landers RJ, Harris AL and Lewis CE: Necrosis correlates with high vascular density and focal macrophage infiltration in invasive carcinoma of the breast. Br J Cancer 79: 991-995, 1999 